\title{
Instructional Supervision in Education Institutions between China and U.S
}

\author{
Guanli Huang, Luyi Chen, Ning Fu, Xiaohong Hu \\ Beijing Polytechnic, Beijing100176, China \\ huangguanli@sina.com
}

\begin{abstract}
The paper identifies different perspectives in the construction of dimensional structure of evaluation scales, namely, instructors' competence perspective, teaching process perspective, learning theories perspective and teaching context perspective. It is suggested that multidimensional and multi-approach evaluation should be applied to comprehensively and truthfully represent teachers' performance, and to facilitate the proper supervisions for teachers in order to promote their professional development.

Index Terms - Instructional supervision, evaluation scales, multi-approach evaluation, Dimensional structures

\section{Introduction}

Teaching quality monitoring and supervision involve many administrative sections and departments. Some Chinese scholars have attempted to categorize education quality assurance system in Chinese universities into three subsystems: namely, teaching administration system, instructional supervision system, including the committee of supervisors at university level or different faculty level, and teaching information system, including teaching inspection information, course evaluation information, students interview information, etc. At present, teaching or instructional supervision system, as an key part of internal self-directed teaching quality assurance system, has been established, and improved in most Chinese universities, playing a central role in guaranteeing the professional competence of their graduates.
\end{abstract}

\section{Definition and Function of Supervision System}

Instructional supervision was originally developed on the basis of education supervision system which functioned to supervise the effective consumption in various schools of educational budget and resources allocated by governmental educational administrations, and to regulate the proper implementation of education policies at the macro level. Education supervision system was first established in France, and later was copied and developed by U. K., U. S. and Japan. However, supervision, as a form of guidance and evaluation of teachers' instructional practice at micro level, was preeminently practiced and developed in U.S.

The pioneering supervision researcher Bolton has defined supervision as "an organized activity to enhance teaching process, involving the task of developing teachers' skills, sorting out teaching materials, evaluating teaching efficacy and appraising teachers' work" . Recent scholars tend to accept the "development view" of supervision, conceptualizing supervision as "a profession to help the inexperienced teacher to acquire or develop instructional knowledge and skills based on the supervisors' expertise". These definitions emphasize the "complementary and supportive" elements of supervision.

Following the definitions, the function of supervision in U.S. has been summarized by an educational researcher Liu Wenjun(2006) as follows: classroom supervision: classroom observation and after-class discussion with teachers may help teachers to solve problems in the teaching process, and to enhance their instructional skills, especially for the new inexperienced teachers who need special consultation for their individualized teaching problems, and who need more support and encouragement for their teaching "debut"; teacher appraisal: school leaders or designated supervisors may regularly note down or evaluate teachers' performance by using classroom checklist or scales, and provide timely feedback to teachers for their further progress. In most cases, supervisors may discuss with teachers about evaluation results and provide constructive advice for their growth. It is worthy to note that, instead of using the evaluation result as a tool to make judgments about teachers' competence, or even to influence leaders' promotion decision, this form of supervision holds the principle of "evaluation for development"; teacher training or development: supervisors are expected to plan and organize some teaching skill workshops or seminars to train instructional skills, to introduce new teaching approaches or model good teaching practice with the aim to update teachers' knowledge and develop new skills.

The comparison in terms of definition and function of supervision system between U.S and China indicates the following difference: Firstly, supervision in American universities attaches great importance to teaching support and service. The main objective of supervision in U.S. is not to make judgment, to help with promotion or punishment decisions, but to exchange experience and improve teaching. By contrast, Chinese universities attribute more weight to administrative monitoring or control in their supervision which could be more suitably labeled as "inspection". In short, the key word is "control" for Chinese system but "support" for the American system. Secondly, teaching supervision in U.S. is regarded as a specialized profession, with teachers as their main service targets; while in china, supervision roles are assumed by some prestigious and experienced professors or school leaders who regard supervision as their sideline. In addition, supervision in China seems to fulfill more functions and covers a wide range of responsibilities.

Like American institutions, Chinese universities also assigned some experienced teachers to be mentors to novice 
teachers, but the mentoring is only limited to class audition. Close collaboration and discussion between mentors and novice teachers are rare.

\section{Big Gap between Supervision and Teaching}

Supervision system in china is mainly run by Education Department in each higher institution. A Teaching Supervision Committee will be organized by the education department to carry out the tasks of routine class observation, teaching materials check-up and information feedback. In recent years, some Chinese universities also realize the importance of teacher development for the improvement of instructional quality, seeking to offer teacher training programs or to model good teaching practice. However, these efforts are still in their trial stage. Teachers are not strongly motivated to participate in these programs to develop their teaching competence. When we look at the composition of supervisors in Chinese and U.S higher institutions, it seems that U.S. regards "professional" as the key trait of supervisors while China reckons "prestigious" as the key trait. Collaboration and collegiality is believed to be more desirable in American teacher-supervisor relationship while hierarchical relationship is commonly observed between Chinese supervisors and teachers. When we compare the operation of supervision system in the two countries, the modern system in U.S. has been existent for over 100 years and played a facilitating role in teaching process, whereas Chinese system has just been introduced from foreign countries. There lies overlap between supervision and teaching administration, but big gap between supervision and teaching.

\section{A. Teaching evaluation approach}

The results indicated the disciplinary differences in students' judgment of satisfactory teaching. Class involvement was believed to be important for effective teaching among education and psychology faculty students, but not so necessary for science students. In fact, there are more researches exploring teaching quality evaluation by means of scales, which seek to reduce a whole series of indicators representing complicated teaching procedure to some important factors which can best and most efficiently explain teaching quality differences. A recent research done by Iranian scholars has sorted out five main factors affecting teachers' instruction: course design, teaching skills, communication skills, disciplinary knowledge and theories, personal traits and professional competence.

\section{B. Dimensional structures of teaching evaluation}

According to a multidimensional point of view concerning teaching process, the instruments used to evaluate teaching should include scales involving a variety of dimensions and indicators. The multidimensional perspective of evaluation yielded a series of researches which explore evaluation dimensions from different perspective and based on different theories. We may categorize the dimensional structures from the following four perspectives.

\section{Dimensional structure from teaching process perspective} The most frequently cited SEEQ( Students' Evaluation of
Educational Quality) in literature was developed by Marsh (1991) following the above construct, he identified a structure of nine principal factors which brought up four second-order factors (see Table 1). The recent research by Apodaca (2005) developed a scale based on the related instruction theory and applied it to 7,318 Spanish university students.

Table1. Dimensional structure of Marsh's 'Student's Evaluation of Educational Quality’ (SEEQ)

\begin{tabular}{|l|l|}
\hline First-order factors & Second-order factors \\
\hline Class design and preparation & I. Presentation \\
\hline Teacher's enthusiasm & \\
\hline Organization/Clarity & \\
\hline Content depth and breadth & \\
\hline Interaction with group & II.Rapport \\
\hline Individual interaction & \\
\hline Exams/Grades & III.Course material \\
\hline Assignments/Reading & \\
\hline Workload/difficulty & IV. Workload \\
\hline
\end{tabular}

Source: Apodaca, P. \& Gradb, H (2005).The dimensionality of student ratings of teaching: integration of uni- and multidimensional models. Studies in Higher Education, 30(6): 723-748.

The confirmatory factor analysis of the data yielded a five-factor model:

1) Instructional preparation and design (course design and teaching content mastery);

2) Teaching skills and enthusiasm (class lecturing and organization skills, enthusiasm, and interest arousal capability);

3) Teacher-student communication skills;

4) Teaching resources (reference material provision, educational technology use)

5) Course assessment criteria.

D. Dimensional structure from learning theories perspective

Some researchers attempted to employ different learning theories to construct dimensional structure of evaluations. Drawing on the behavioral point of view, Davis (1977) advanced eight criteria for the evaluation of teaching experiences:

1) Proper context of the learning;

2) Appropriate technology to facilitate learning;

3) Students' active participation;

4) Different ways for the student to respond to the same concept or idea;

5) Approaching concepts from a variety of viewpoints;

6) Appropriate and specific feedback;

7) Individualized instruction;

8) Efficient organization of teaching subject content. From an information-processing perspective (Brown \& Atkins, 
1988), effective lecturing can be analyzed according to the following dimensions:

1). Intentions and planning: preparation, information of goals and work plans;

2) Information transmission: clarity, expressiveness;

3) Information reception: keeping student's attention, facilitating long-term memory;

4) Output: students' reactions, learning outcomes.

E. Dimensional structure from teaching context perspective

Different faculties in a university can be regarded as different epistemological and social communities, presenting difference in epistemic concern, patterns of communication, working styles and academic context. The diversity of disciplinary cultures have pointed out that university is not a coherent entity but consists of a variety of "academic tribes". Since each academic discipline has different teaching content, teaching objectives and goals, instructional evaluation should avoid the risk of forcing the same evaluating criteria on all disciplinary fields, but instead, taking discipline variables into consideration. Based on the evaluation results derived from scales and intensive interview with students from different disciplines, Italian researcher Ghedin (2008) has adopted "contextuality view of teaching" and identified two major categories in evaluation process :

Instruction category:

1) Teachers' personal traits and professionalism;

2) Teaching skills;

3) Teachers' capability to motivate students;

4) Assessment approach

Teaching context category:

1) Education policies and regulations;

2) Curriculum design;

3) Course objective and content;

4) Management of teaching affairs (facilitating studentteacher coordination)

The characteristics of a "good teacher" or of the "interesting course" vary from faculty to faculty since the learning needs and disciplinary contents are diverse. It is necessary to have an evaluation scale or criteria applicable to all faculties in a university, but more importantly, to develop the appropriate scales to address, with dynamic and flexibility, the different requirement or focus of teaching in different faculties.

Other researches probed into the influence of classroom environment on teaching practice (Scheerens, 2007). These environment factors include class size, students composition, teachers' expectation, match between students' learning style and teachers' instructional style, etc. Hoveida and his research group also found that students' uncertainty about future career opportunity, students' incapacity to cope with disciplinary requirement will also function as the contextual factors influencing evaluation results. The implications of these studies all indicate that teaching quality is not only tied to instructional competence, but also connected with a variety of contextual elements which make the teaching and evaluation process diverse, dynamic and context-dependent.
The literature review revealed approximately balanced number of qualitative and quantitative researches on teaching evaluation, with qualitative study showing increasing tendency which reflects the multidimensionality and complexity of teaching process. We cannot draw a reliable evaluation conclusion based on information collected from the single dimension, single source and single appraisal. In addition, supervisors should be cautious in the explanation of evaluation results, taking the specific instructional situation into consideration. It is worthy to mention that application of evaluation results should be reasonable and appropriate, that is to say, the results can be a valuable reference for teachers' instructional improvement, but cannot be directly linked to salary increment or professional promotion.

\section{Implications for the Development of Instruction Supervision System}

By contrast, supervision in Chinese higher institutions focuses on the "accountability" goal, that is, to make teachers accountable for their teaching performance by regular evaluations. The major concern is whether the teachers have effectively and responsibly completed their teaching tasks. The usual supervision practices in Chinese universities, such as mid-term class observation, teaching material check-up and end-term students' evaluation of teachers' performance are primarily meant to perform the "monitoring and judgment" functions.

Undoubtedly, evaluation should be an important component of supervision, but its role cannot be exaggerated to represent the full function range of supervision. There are some cases, aptly labeled "evaluation without guidance", in which the supervisors are preoccupied with class observation and scale rating, then submitting an evaluation report to school leaders without giving feedback and counseling service to teachers. On the other hand, we also observed some supervisors or mentors who, without a systematic and valid evaluation, venture to provide guidance or suggestions to inexperienced teachers. They are practicing so called "guidance without proper evaluation". Nowadays more and more researchers prefer the "development view" of supervision. Valid and reliable teaching evaluation has been a debatable topic in supervision. It is generally accepted that the information derived from a single source, a single observation or a single dimension cannot be sufficient for reliable assessment. Therefore, multidimensional and multi-approach assessments are encouraged to be applied to reduce the bias to a minimum. With regard to the evaluation approaches, class observation, scale rating and students' interview are the usual ways to get teaching performance information. The combination of these approaches can enable us to have a holistic and comprehensive judgment of teachers' performance. With regard to the content of evaluation, different dimensional structures are constructed based on instructors' competence perspective, teaching process perspective, learning theory perspective and teaching context perspective. It is not possible and necessary to develop a unified dimensional structure for 
all evaluation scales since the teaching process is so complicated and dynamic. We might as well choose or adapt a scale with dimensional structure that best suits our specific teaching context.

Following the new trend of supervision, Chinese higher institutions should learn from U.S. side and re-orient their supervision from "evaluative/judgmental mode" to "supportive mode" so that teachers may turn their aversive attitude toward supervisors to welcoming attitude, feeling they are not being judged, but being helped. Some professional supervisors with specialized training in education sciences could be employed to facilitate the build-up and development of the supervision system. Moreover, instruction evaluation should reflect the specific context of Chinese higher education, applying data from multiple dimensions and sources to truthfully, objectively and scientifically describe teachers' performance. Above all, an appropriate supervision system could enable teachers to have higher self-efficacy in teaching and could create infinite possibilities for teachers' professional growth.

Take New Mexico University, School of Medicine for an example (a school the author had visited and learned about its supervision system), the education department designates two offices to be responsible for teaching supervision, namely, Office of Teacher Development and Office of Course Evaluation. Office of Teacher Development will regularly organize training programs or workshops to impart education theories and teaching skills to teachers. All novice teachers have to attend these training programs and get the training course credits before they take up the real teaching responsibilities. Office of Course Evaluation is mainly responsible for the evaluation of course design and teaching efficacy, collecting the suggestions provided by students and supervisors, and then giving feedback to course teachers.

\section{Relationship between Supervision and Evaluation}

As mentioned above, evaluation is an important component of supervision. Both China and U.S. define evaluation as a necessary function of the supervision system. Moreover, evaluation is the prerequisite for the effective implementation of other supervision functions. Only with objective and just evaluation, can proper and effective teaching consultation be provided at the micro level, and instrumental training courses be devised at the macro level. In fact, "inspection", "evaluation" and "guidance" are three closely interrelated steps in supervision process with evaluation connecting the other two.
Needless to say, evaluation is of vital importance for the effective teaching supervision. Nevertheless, it seems to be extremely difficult to have comprehensive and objective evaluation of teaching due to a variety of factors influencing teaching activity and the complicated and dynamic interactions between these factors. Research literatures seldom come to agreement with regard to evaluation approach, criteria and dimensions. Different researchers tried to explore teaching evaluation from different perspective, but none of them could propose a unified, comprehensive evaluation criterion. Hereafter the author will summarize the literatures related to teaching evaluation.

\section{Acknowledgment}

The work sponsed by National Grant for Pilot Study on Educational System Reform in China: Construction of teaching evaluation dimensions and norms of Education item in Beijing Polytechnic College (Grant number: PXM2013_014306_ 000073) .

\section{References}

[1] Guo, X.D.(2007), Construction of teaching quality assurance system in higher institutions. China Education Daily, 2007. 8: 10(3).

[2] Hastings, W. \& Squires, D. (2002). Restructuring and Reculturing: practicum supervision as professional development for teachers. AsiaPacific Journal of Teacher Education, 30(1): 79-91.

[3] Hazi, H. (1994). The teacher evaluation-supervision dilemma: a case of entanglements and irreconcilable differences. Journal of Curriculum and Supervision 9 (2), 195-216.

[4] Hoveida, R., Moulavi, H. (2008). Improvement teaching quality process of faculty member's viewpoint in Esfahan University. Iranian Journal AQIP 8 (1): 132-141.

[5] Li, Z. P.,Li. X. (2008), Theories and empirical study on teaching supervision in Chinese universities. Heilongjiang Researches on Higher Education, 2008(5):84-86.

[6] Liu, W. J. (2007), Present system of American instructional supervision and its characteristics. Comparative Education Review, 2007(7): 12-16

[7] Marsh, H. W. (1991) Multidimensional student's evaluation of teaching effectiveness: a test of alternative higher-order structures, Journal of Educational Psychology, 83:285-296.

[8] Wan, S. Z. (2011), Review of instruction supervision system in Chinese higher institutions. Heilongjiang Researches on Higher Education. 2011(3):51-53.

[9] $\mathrm{Wu}, \mathrm{M}$. H., A tentative probe into supervision work in Chinese higher institutions.Journal of Nanjing Traditional Chinese Medical University (Social Science Edition), 2001, 2(4): 212 213.

[10] Zhu, J. Z. (2005), Roles and responsibilities of teaching supervisors in higher educational institutions. Jiangsu Higher Education, 2005(1): 6264.

[11] Ralph, E. (2000). Aligning mentorship style with beginning teachers' development: Contextual supervision. The Alberta Journal of Educational Research, 46(4): 311-326. 